\title{
Green synthesis of zinc oxide nanoparticles using aqueous extract of Garcinia mangostana fruit pericarp and their photocatalytic activity
}

\author{
MOHAMMOD AMINUZZAMAN ${ }^{1, *}$, LIM POH YING ${ }^{1}$, WEE-SHENOG GOH ${ }^{1}$ and \\ AKIRA WATANABE ${ }^{2}$ \\ ${ }^{1}$ Department of Chemical Science, Faculty of Science, Universiti Tunku Abdul Rahman (UTAR), Perak Campus, Jalan \\ Universiti, Bandar Barat, 31900 Kampar, Malaysia \\ ${ }^{2}$ Institute of Multidisciplinary Research for Advanced Materials (IMRAM), Tohoku University, Katahira 2-1-1, Aoba-ku, \\ Sendai 980-8577, Japan \\ *Author for correspondence (mohammoda@utar.edu.my)
}

MS received 16 June 2017; accepted 15 August 2017; published online 29 March 2018

\begin{abstract}
We reported a facile, green and eco-friendly approach for the synthesis of zinc oxide nanoparticles (ZnO NPs) using aqueous extract of Garcinia mangostana (G. mangostana) fruit pericarp as reducing agent as well as capping agent. Biosynthesized ZnO NPs were characterized by various analytical tools using X-ray diffraction, Fourier transform infrared spectroscopy, field emission scanning electron microscopy, transmission electron microscopy, energy dispersive X-ray spectroscopy and UV-Vis spectroscopy. The results showed that ZnO NPs synthesized by aqueous extract of G. mangostana fruit pericarp with high purity, mostly spherical in shape with an average size of $21 \mathrm{~nm}$. The photocatalytic activity of biosynthesized ZnO NPs was evaluated by carrying out the degradation of malachite green dye under solar irradiation. The extent of MG dye degradation was monitored spectrophotometrically by measuring absorbance at its characteristics $\lambda_{\text {max }}$ value of $615 \mathrm{~nm}$. Degradation products were detected using liquid chromatography-mass spectrophotometry technique. The biosynthesized $\mathrm{ZnO}$ NPs showed an excellent photocatalyst performance due to the small size and high purity.
\end{abstract}

Keywords. Green synthesis; $\mathrm{ZnO}$ nanoparticles; photocatalyst; dye; photodegradation.

\section{Introduction}

The discharge of dye effluents from various industries such as dye stuffs, textiles, paint and varnishes, inks, plastics, pulp and paper, food, rubber, and cosmetics to the environment is a prime cause of concern nowadays [1]. The effluents from these industries cause the water bodies not only to become coloured, but also lead to a reduction in sunlight penetration, decreasing photosynthetic activity, dissolved oxygen concentration and water quality; and having acute toxic effects on aquatic plants, causing severe environmental problems worldwide [2]. In addition, many synthetic dyes and their metabolites are toxic, mutagenic and carcinogenic [3]. Hence, it is necessary and vital to treat the dye effluents prior to discharge into the environment (receiving water). As dyes are generally stable to light, oxidizing agent and have poor biodegradability, removal of dyes from industrial effluents is considered as a challenging problem in the control of environmental pollution. Biological treatment, activated carbon adsorption, ion-exchange and chemical coagulation are some of the conventional treatment processes of dye removal, but all these still have their own disadvantages and limitations [4-7]. Though activated carbon has proven its efficiency and capability in removing various types of pollutants due its high porosity and large surface area $\left(500-200 \mathrm{~m}^{2} \mathrm{~g}^{-1}\right)$, but widespread application is restricted due to high cost, difficult disposal and regeneration [8]. Therefore, research is intensified to search for new materials to serve as the potential alternative to dye removal from wastewater. Photocatalytic purification of wastewater using semiconductor nanomaterials such as $\mathrm{ZnO}, \mathrm{TiO}_{2}, \mathrm{CuO}$, etc., has attracted tremendous interest nowadays because of their nontoxicity, high photocatalytic efficiency, high physical and chemical stabilities and cost-effectiveness. $\mathrm{ZnO}$ is a versatile $n$-type semiconductor with excellent chemical and thermal stabilities with wide band gap of $3.37 \mathrm{eV}$ and high excitation binding energy of $60 \mathrm{meV}$ at room temperature [9]. Hence, it is considered as one of the potential photocatalysts for the degradation of various pollutants in wastewater. The photocatalytic activity of $\mathrm{ZnO}$ can be augmented using nanosized $\mathrm{ZnO}$ in the form of various shapes as nanoparticles, nanorods, nanotubes, etc. As the reduction in size increases the surface area, thus, enhancing the photocatalytic activity of $\mathrm{ZnO}$. A number of physical and chemical approaches are available to synthesize $\mathrm{ZnO}$ nanoparticles ( $\mathrm{ZnO} \mathrm{NPs}$ ), for example, hydrothermal method [10], solvothermal method [11,12], microemulsion method [13], microwave method [14], thermal decomposition [15], precipitation [16], sol-gel [17], laser ablation [18] and 
sonochemical method [19]. Although these physical/chemical methods are effective to synthesize of $\mathrm{ZnO}$ NPs with different sizes and morphologies, but these methods are complex, and utilize hazardous organic solvents, toxic reagents, nonbiodegradable stabilizing agents and expensive instruments along with the tedious process control. Therefore, there is great demand for developing a simple, safe and eco-friendly method for synthesizing $\mathrm{ZnO}$ NPs.

Biological synthesis of nanoparticles using plant extracts is becoming an emerging area of research in nano-biotechnology due to its simplicity, low cost, nontoxicity and environmentally friendly nature. Moreover, nanoparticles are produced by plant extracts are more stable and biocompatible in comparison with those produced by physical/chemical methods. Based on the literature, biosynthesis of $\mathrm{ZnO}$ NPs were reported by using plant extracts including Aloe vera (leaf) [20], Nephelium lappaceum L. (fruit peel) [21], Corymbia citriodora (leaf) [22], Polygala tenuifolia (root) [23], Trifolium pratense (flower) [24], Rosa canina (fruit) [25], Zingiber officinale (rhizome) [26], Eucalyptus globulus (leaf) [27] and Vitex trifolia L. (leaf) [28]. In the present work, we describe a green synthetic strategy to prepare ZnO NPs from Garcinia mangostana fruit pericarp extract. Garcinia mangostana L. (G. mangostana) is commonly known as mangosteen, and belongs to the family of Guttiferae. It can grow up to 6-25 $\mathrm{m}$ in height and is mainly found in Southeast Asian countries such as Indonesia, Malaysia, Vietnam, Thailand, Philippines and Sri Lanka. Mangosteen has dark purple to red-purple fruits. The edible portion of fruit (aril) is white, soft with a slightly sour taste and a pleasant aroma. It is the most economical and popularly consumed tropical fruits in the Southeast Asian countries. Consequently, large amounts of mangosteen pericarp
(6-10 $\mathrm{mm}$ in thickness) are discarded as waste domestically. There are few applications of these pericarps were reported in the literature, for example, the pericarp was used in folk medicine in treatment of several human illnesses, including skin and wound infections, hemorrhoids, arthritis, tuberculosis, inflammation, genitourinary tract infections, fever and amoebic dysentery [29], and as biosorbents to remove toxic metals of $\mathrm{Pb}$ (II), $\mathrm{Cd}$ (II) and $\mathrm{Co}$ (II) from aqueous solution [30]. Another application includes their use as an effectual component as a sensitizer to fabricate dye-sensitized solar cells [31].

Herein, we demonstrate a green and eco-friendly route for the synthesis of $\mathrm{ZnO}$ NPs using aqueous extract of G. mangostana fruit pericarp. X-ray diffraction (XRD), energy dispersive X-ray spectroscopy (EDX), field emission scanning electron microscope (FESEM), transmission electron microscopy (TEM), Fourier transform infrared spectroscopy (FTIR) and UV-Vis spectroscopy were used for characterizing the biosynthesized ZnO NPs. The photocatalyst activity of biosynthesized $\mathrm{ZnO}$ NPs was also investigated using malachite green (MG) dye as the model pollutant under solar irradiation.

\section{Experimental}

\subsection{Materials}

G. mangostana fruits were purchased from a local market Kampar, Malaysia. Zinc nitrate hexahydrate $\left(\mathrm{Zn}\left(\mathrm{NO}_{3}\right)_{2}\right.$. $6 \mathrm{H}_{2} \mathrm{O}$ ) and $\mathrm{MG}$ dye were purchased from Sigma-Aldrich, USA, and used as received. All aqueous solutions were prepared using distilled water. All glassware used was cleaned and washed with distilled water and dried before use.

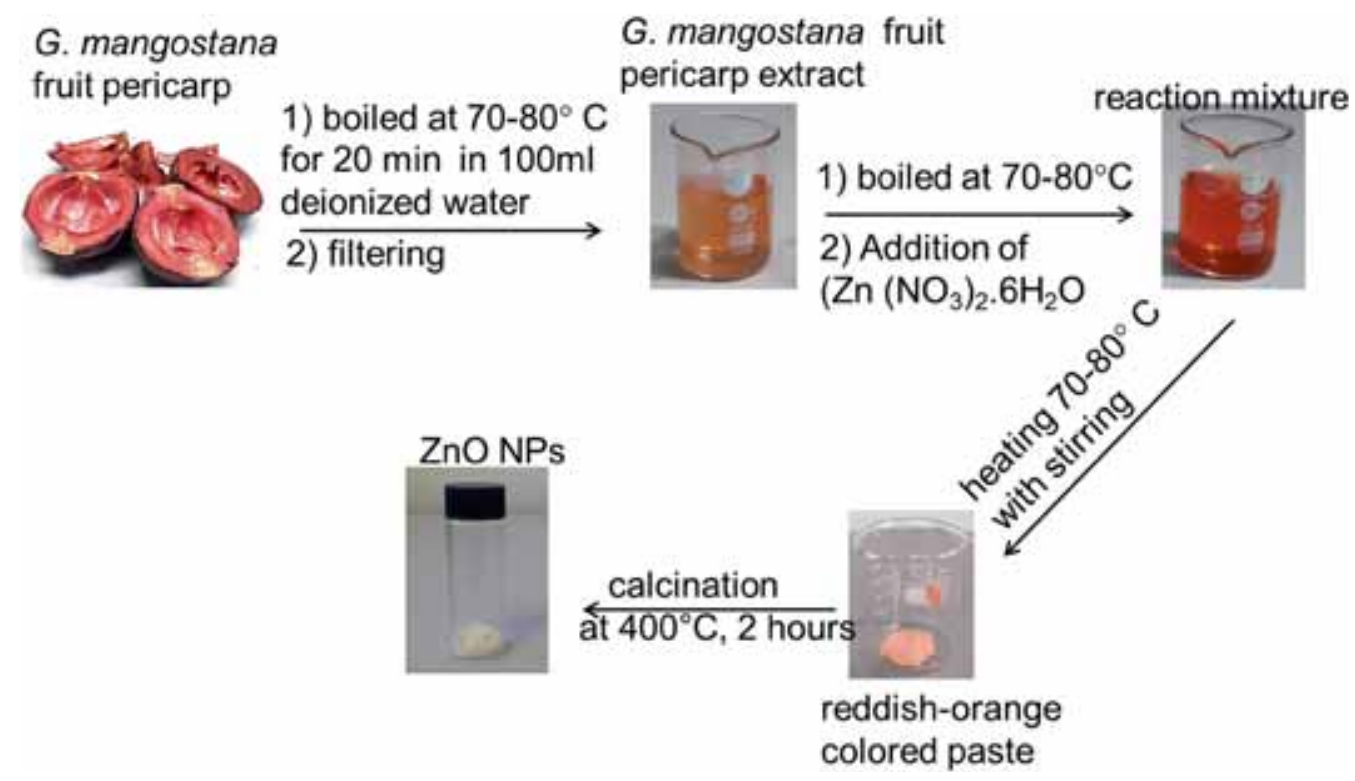

Scheme 1. Steps involved in biosynthesizing of ZnO NPs using aqueous extract of Garcinia mangostana fruit pericarp. 


\subsection{Preparation of aqueous extract of $G$. mangostana fruit pericarp}

The fresh pericarps were washed thoroughly with distilled water to remove dust and organic impurities. About $8 \mathrm{~g}$ of pericarps were taken in a $250 \mathrm{ml}$ beaker containing 100 $\mathrm{ml}$ deionized water and then, the pericarps were boiled at $70-80^{\circ} \mathrm{C}$ for $20 \mathrm{~min}$. During the procedure of boiling, a pale brown coloured solution was formed and which was cooled at room temperature. Then, the extract was filtered with filter paper (Whatman no. 1) twice and filtrate was collected in a $100 \mathrm{ml}$ beaker. This extract was then directly used in the synthesis of $\mathrm{ZnO}$ NPs.

\subsection{Synthesis of ZnO NPs}

Scheme 1 represents the synthesis of $\mathrm{ZnO}$ NPs using aqueous extract of G. mangostana fruit pericarp. To synthesize $\mathrm{ZnO}$ NPs, freshly prepared $50 \mathrm{ml} \mathrm{G}$. mangostana fruit pericarp extract was taken in $100 \mathrm{ml}$ beaker and boiled at $70-80^{\circ} \mathrm{C}$. Later, about $4 \mathrm{~g}$ of zinc nitrate hexahydrate $\left(\mathrm{Zn}\left(\mathrm{NO}_{3}\right)_{2} \cdot 6 \mathrm{H}_{2} \mathrm{O}\right)$ was added slowly into the hot pericarp extract and immediately reddish-brown coloured solution was formed. This reaction mixture was heated at $70-80^{\circ} \mathrm{C}$ with magnetic stirring. As the reaction progressed, the colour of the reaction solution slowly changed from reddish-brown to pale yellow and heating continued until the formation of reddish-orange coloured paste. The paste was then transferred to a ceramic crucible followed by heating in a furnace at $400^{\circ} \mathrm{C}$ for $2 \mathrm{~h}$. The obtained pale white coloured powder was used for further studies.

\subsection{Characterization}

The crystal phase information of the sample was characterized from 10 to $80^{\circ}$ in $2 \theta$ by an X-ray diffractometer with $\mathrm{CuK} \alpha$ radiation (Shimadzu XRD 6000, Japan). Surface morphology of ZnO NPs was characterized by FESEM (JEOL JSM-6701F combined with EDX, Japan) and high resolution transmission electron microscope (HRTEM) (JEOL JEM 3010). UV-Vis absorption spectra were recorded by a UV-visible spectrophotometer (Perkin Elmer Lambda 35). The FTIR spectra of biosynthesized ZnO NPs were recorded by KBr pellet method using FTIR spectrophotometer (Perkin Elmer RX1).

\subsection{Photocatalytic activity of $\mathrm{ZnO} \mathrm{NPS}$}

The photocatalytic activity of the biologically synthesized $\mathrm{ZnO}$ NPs was evaluated by the degradation of an organic dye, MG under direct sunlight. In a typical process, $50 \mathrm{mg} \mathrm{ZnO}$ NPs were added into a beaker containing MG dye solution $\left(50 \mathrm{ml}, 10 \mathrm{mg} \mathrm{l}^{-1}\right)$. Prior to exposure to sunlight, the suspension was magnetically stirred in the dark for $30 \mathrm{~min}$ to reach the adsorption-desorption equilibrium. The photodegradation of MG dye was carried out on a sunny day between 11 am and $2 \mathrm{pm}$ when there were minimum fluctuations in solar

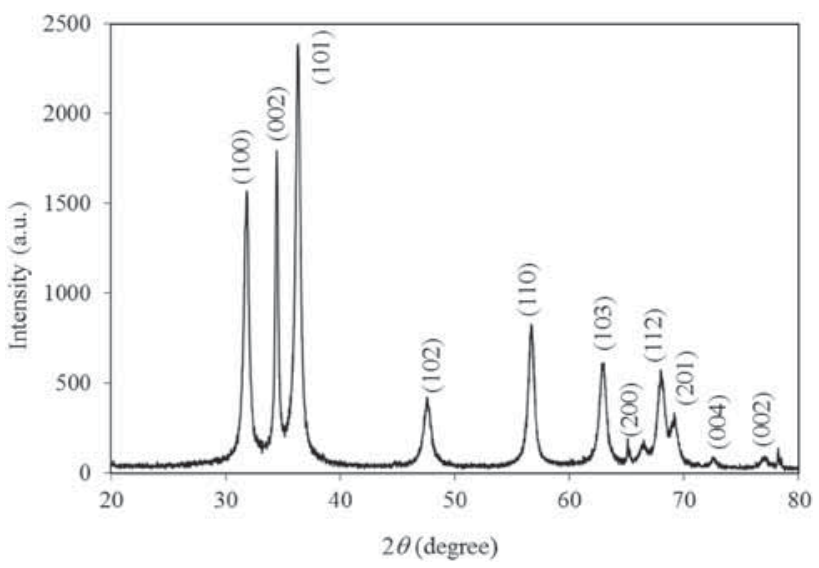

Figure 1. XRD pattern of biosynthesized ZnO NPs using G. mangostana fruit pericarp extract.

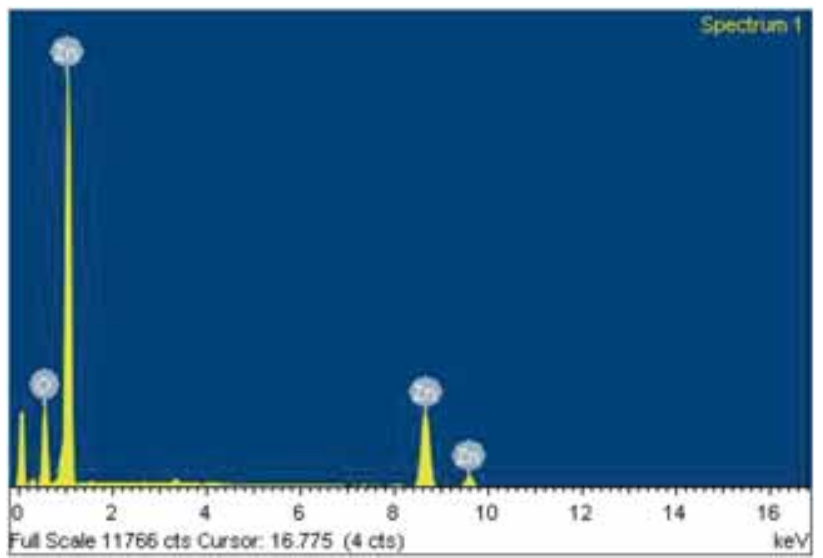

Figure 2. EDX spectrum of biosynthesized $\mathrm{ZnO}$ NPs.

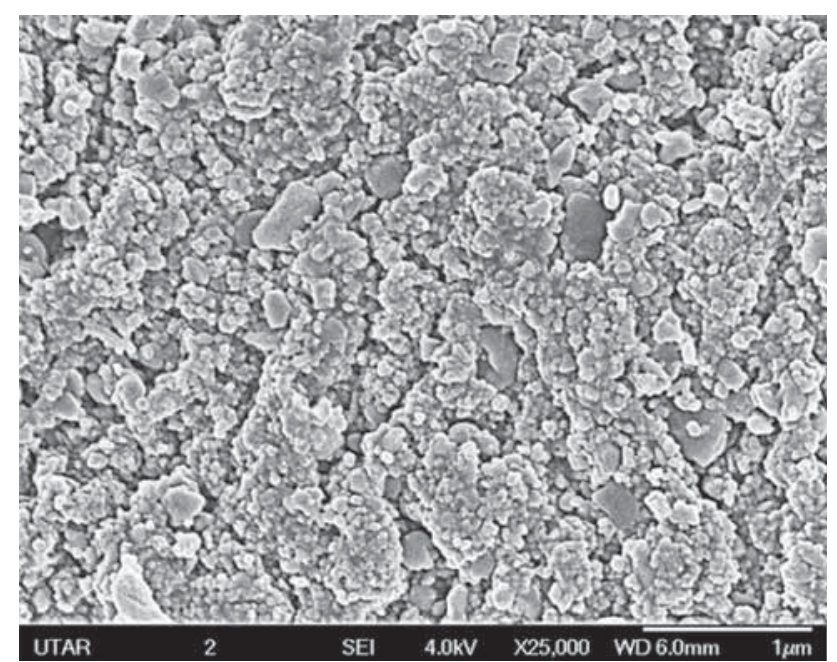

Figure 3. FESEM image of green-synthesized ZnO NPs.

intensity. The experiment was carried out in UTAR, Kampar campus in the month of February (outside temperature 

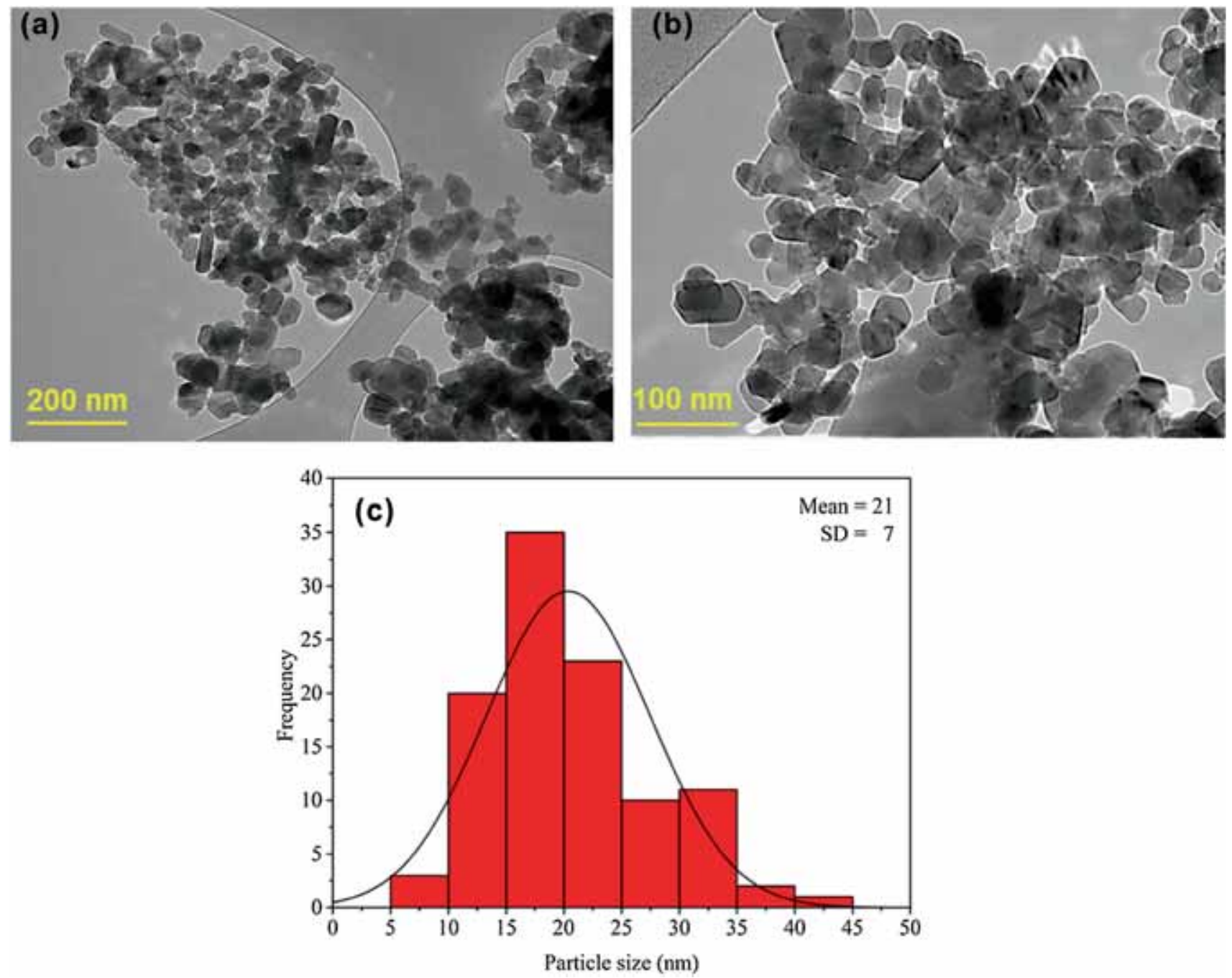

Figure 4. TEM images of ZnO NPs forms using G. mangostana fruit pericarp extract and histogram of particles size distribution of $\mathrm{ZnO}$ NPs.

was $30-35^{\circ} \mathrm{C}$ ) on a sunny day when the average solar radiation was $4.35 \mathrm{kwh} \mathrm{m}^{-2} \mathrm{~d}^{-1}$. At given time intervals, $10 \mathrm{ml}$ of suspension was sampled and centrifuged $(7000 \mathrm{rpm})$ for $10 \mathrm{~min}$, the supernatant was collected for absorption analysis on a UV-Vis spectrophotometer. The absorbance of MG at $615 \mathrm{~nm}$ was used to measure the residual dye concentration. The degradation efficiency (\%) was calculated using the below mentioned equation:

$$
\text { Degradation efficiency }(\%)=\frac{C_{\mathrm{o}}-C}{C_{\mathrm{o}}} \times 100 \text {, }
$$

where $C_{\mathrm{o}}$ is the initial concentration of $\mathrm{MG}$ dye solution $\left(\mathrm{mg} \mathrm{l}^{-1}\right)$ and $C$ the concentration of the MG dye solution $\left(\mathrm{mg} \mathrm{l}^{-1}\right)$ after a certain irradiation time.

Moreover, possible intermediates formation during photocatalytic degradation of MG dye were determined by liquid chromatography-mass spectrophotometry (LC-MS) analysis

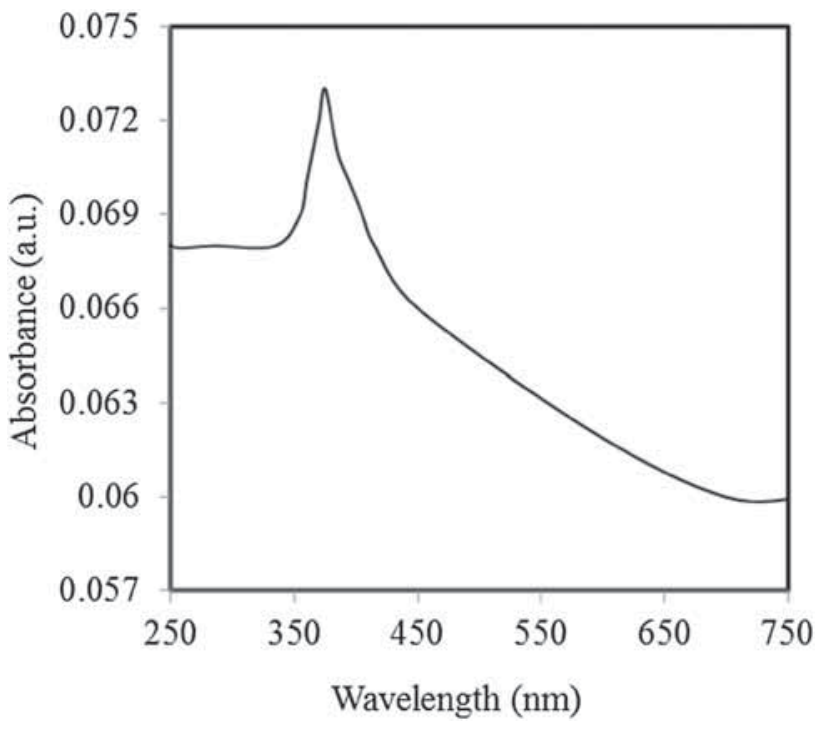

Figure 5. UV-Vis spectrum of biosynthesized ZnO NPs. 
of degraded dye solution taken at different time intervals using an Agilent 6520 Accurate-Mass Q-TOF LC/MS (Agilent, USA) instrument. The mobile phase was a mixture of

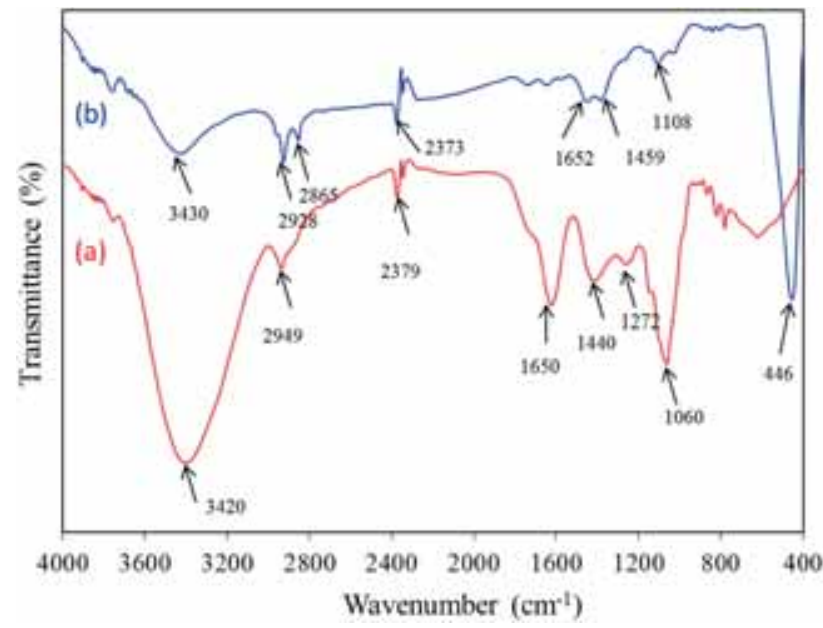

Figure 6. FTIR spectra of (a) pure G. mangostana fruit pericarp extract and (b) biosynthesized $\mathrm{ZnO}$ NPs by using G. mangostana fruit pericarp extract.

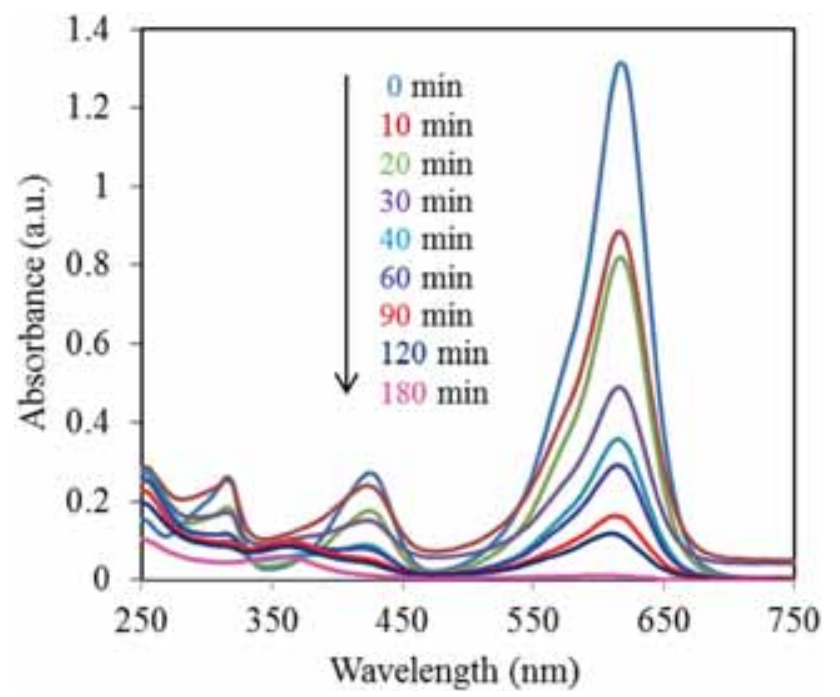

Figure 7. Time-dependent UV-Vis absorption spectra of photocatalytic degradation of MG dye in the presence of biosynthesized $\mathrm{ZnO}$ NPs. water (A) and acetonitrile (B) at $0.6 \mathrm{ml} \mathrm{min}{ }^{-1}$ of the flow rate, and the gradient was set as follows: $t=0 \mathrm{~min}, \mathrm{~A}: \mathrm{B}=$ 5:95 (V/V); $t=30 \mathrm{~min}, \mathrm{~A}: \mathrm{B}=95: 5(\mathrm{~V} / \mathrm{V})$. The column temperature was $30^{\circ} \mathrm{C}$ and injection volume was $20.00 \mu \mathrm{l}$ using autosampler. The mass fragments to monitor were from 40 to $400 \mathrm{~m} / \mathrm{z}$.

\section{Results and discussion}

\subsection{Characterization of green synthesized ZnO NPs}

XRD technique was used to examine the crystal phases and crystallinity of the synthesized ZnO NPs. Figure 1 represents the XRD pattern of biosynthesized ZnO NPs. The distinct diffraction peaks at $2 \theta=31.81,34.44,36.24,47.52,56.64$, $62.82,65.12,66.32,67.98,69.14,72.56$ and $77.14^{\circ}$ were assigned to (100), (002), (101), (102), (110), (103), (200), (112), (201) (004) and (002) planes, respectively. In figure 1, all the diffraction peaks were well indexed to the hexagonal phase (wurtzite structure) of $\mathrm{ZnO}$, which are very close to standard values (JCPDS no. 36-1451). Similar XRD results were also observed in the reported literature for $\mathrm{ZnO}$ nanomaterials [32,33]. Interestingly, no reflection related with any impurity was detected in the pattern, up to the detection limit of XRD diffractometer, which further reveals that the prepared nanoparticles are pure $\mathrm{ZnO}$. Moreover, the obtained diffraction reflections are well-defined with high intensity, which clearly confirmed that the biosynthesized ZnO NPs are wellcrystalline. The crystallite size $(D)$ of the biosynthesized $\mathrm{ZnO}$ NPs was calculated by Debye-Scherrer's equation i.e.,

$$
D=\frac{0.94 \lambda}{\beta \cos \theta}
$$

where $\lambda$ is the wavelength $(\mathrm{CuK} \alpha), \beta$ the full-width halfmaximum (FWHM) and $\theta$ the diffraction angle. The average crystallite size was found to be $23.56 \mathrm{~nm}$. The elemental information of the biosynthesized ZnO NPs was analysed by EDX. As shown in figure 2, the spectrum of the sample presents only the existence of zinc $(\mathrm{Zn})$ and oxygen $(\mathrm{O})$. No other peak related with any other impurity was detected in the spectrum suggesting the high purity of formed ZnO NPs. Moreover, the weight percentage of zinc and oxygen was calculated to be 71.9 and $28.1 \%$, respectively, which is in agreement with

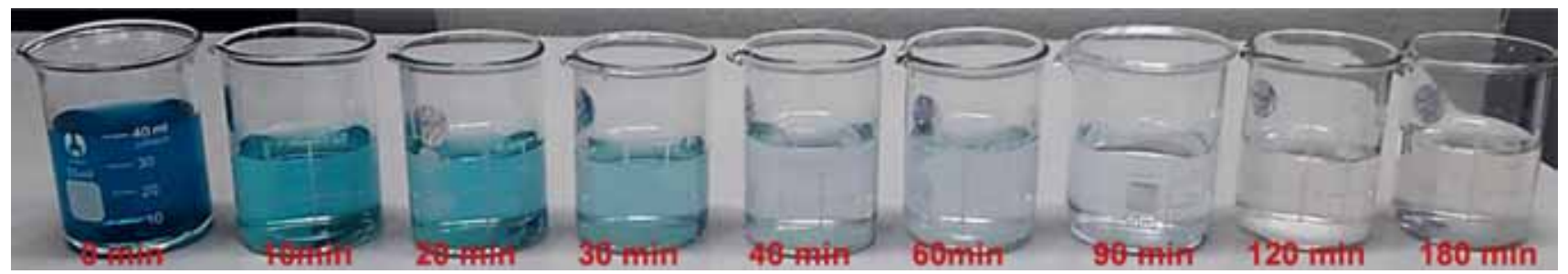

Figure 8. Photograph shows gradual change in MG dye colour from bluish-green to colourless by solar irradiation. 
those previously reported [34,35]. FESEM image of biosynthesized $\mathrm{ZnO}$ NPs is presented in figure 3 revealing that $\mathrm{ZnO}$ NPs with nearly spherical morphology and are agglomerated

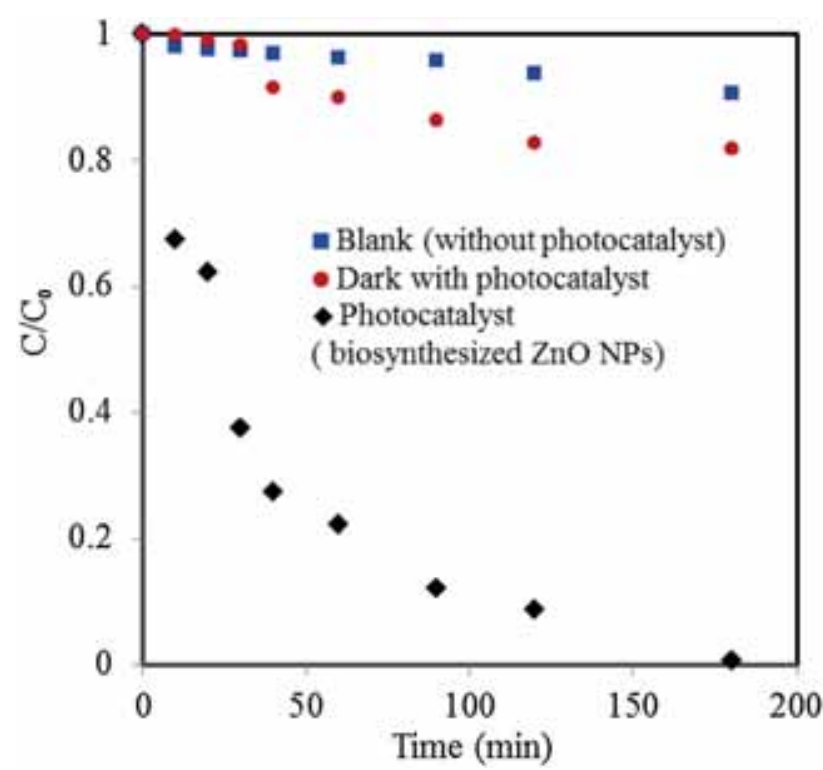

Figure 9. Degradation of MG dye solution as a function of different time intervals. as a result of polarity and electrostatic attraction of nanoparticles. The size, shape and morphology of the green synthesized $\mathrm{ZnO}$ NPs were also investigated using TEM, which is represented by figure 4 . TEM images indicate the shape of ZnO NPs are mostly spherical and some hexagonal shape particles are also seen in the micrograph. Figure $4 \mathrm{c}$ displays the histogram of the distribution of the particle size of $\mathrm{ZnO}$ NPs showing that typical sizes of the $\mathrm{ZnO}$ NPs are in the range between 5 and $45 \mathrm{~nm}$ and the average mean size was $21 \mathrm{~nm}$, which is quite similar to the value obtained from XRD measurement.

The room temperature UV-Vis absorption spectrum of the biosynthesized $\mathrm{ZnO}$ NPs is shown in figure 5. The ZnO NPs were dispersed in water with a concentration of $0.1 \mathrm{wt} \%$ and the solution was used to perform the UV-Vis measurement. The spectrum reveals a characteristic absorption peak at wavelength of $375 \mathrm{~nm}$ which can be assigned to the intrinsic band-gap absorption of $\mathrm{ZnO}$ due to the electron transitions from the valence band to conduction band $\left(\mathrm{O}_{2 \mathrm{p}} \rightarrow \mathrm{Zn}_{3 \mathrm{~d}}\right)$. The band gap energy $\left(E_{\mathrm{g}}\right)$ of the $\mathrm{ZnO} \mathrm{NP}$ is calculated using the following equation:

$$
E_{\mathrm{g}}=h c / \lambda,
$$

where $h$ is the Planck's constant $\left(6.662 \times 10^{-34} \mathrm{Js}\right), c$ the velocity of light $\left(3 \times 10^{8} \mathrm{~m} \mathrm{~s}^{-1}\right)$ and $\lambda(375 \mathrm{~nm})$ the wavelength. The band gap energy for the $\mathrm{ZnO}$ NPs was found to be $3.32 \mathrm{eV}$.

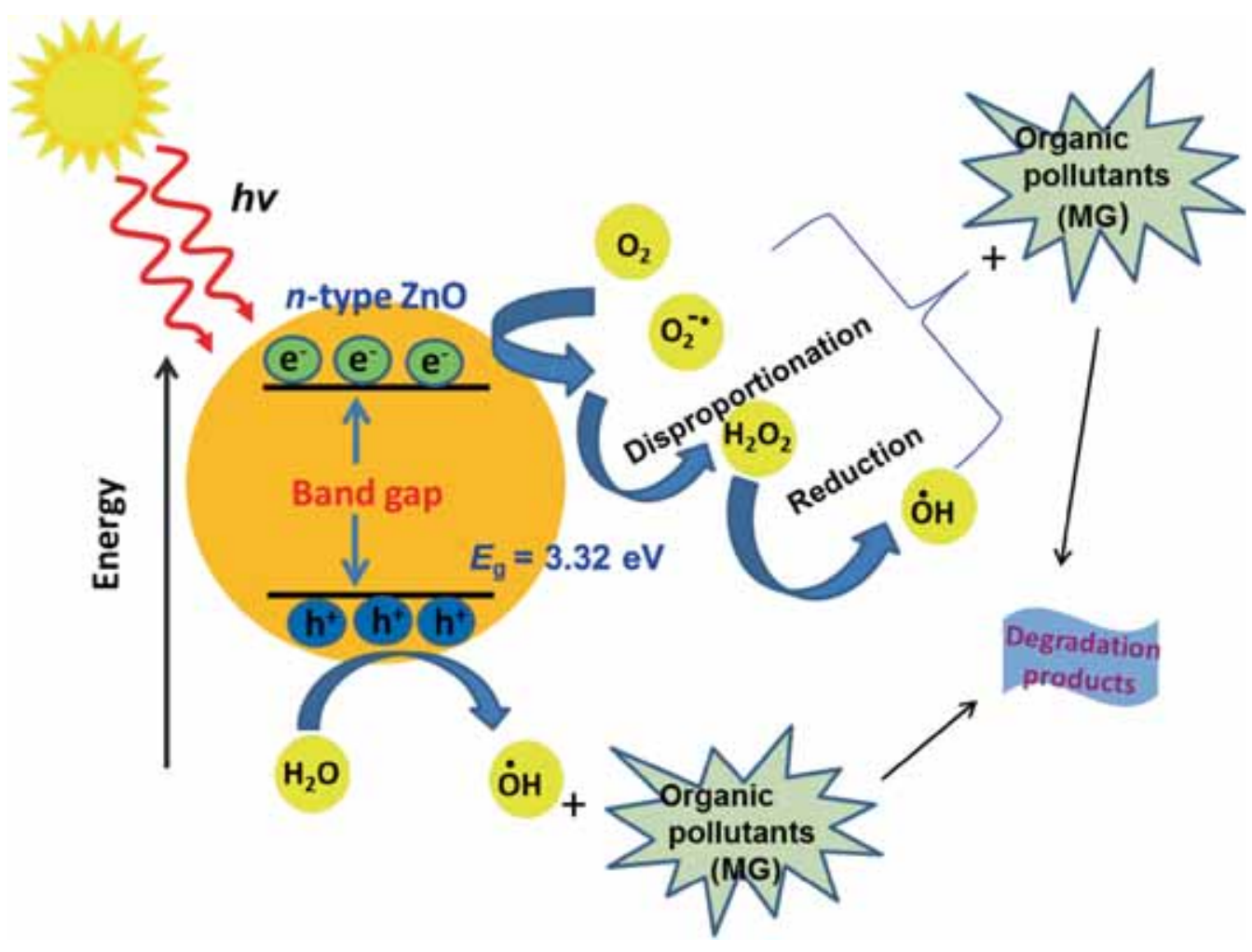

Scheme 2. Photocatalytic reaction mechanism of biosynthesized ZnO NPs. 
ZnO NPs (3.32 eV) show blue shift compared to bulk $\mathrm{ZnO}$ $(3.37 \mathrm{eV})$ and this observed blue shift may be due to the size effect [36].

FTIR was carried out to determine the potential functional groups of biomolecules that are responsible for the formation of $\mathrm{ZnO}$ NPs. Figure 6 shows the spectra obtained from pure G. mangostana pericarp extract and ZnO NPs synthesized using $G$. mangostana pericarp extract. The absorption bands at 3420 and $2949 \mathrm{~cm}^{-1}$ indicate the presence of $\mathrm{O}-\mathrm{H}$ and $\mathrm{C}-\mathrm{H}$ stretchings. The absorption peak is located at around
$1650 \mathrm{~cm}^{-1}$ represents $\mathrm{C}=\mathrm{O}$ stretching. The bands at 1440 and $1272 \mathrm{~cm}^{-1}$ are associated with the $\mathrm{C}-\mathrm{C}$ stretch (in ring) of the aromatic group and $\mathrm{C}-\mathrm{OH}$ vibrations of polyols. Finally, the absorption peak at $1060 \mathrm{~cm}^{-1}$ is attributed to $\mathrm{C}-\mathrm{O}-\mathrm{C}$ stretch. All the above results indicate phenol, flavonoid, xenthone and anthocyanin compounds are abundant in pericarp of G. mangostana [37]. On the other hand, the FTIR spectra of biosynthesized ZnO NPs have shown a sharp and intense absorption peak at $446 \mathrm{~cm}^{-1}$ confirming the stretching vibration of $\mathrm{Zn}-\mathrm{O}$ [21] and very weak absorption bands at 3430,
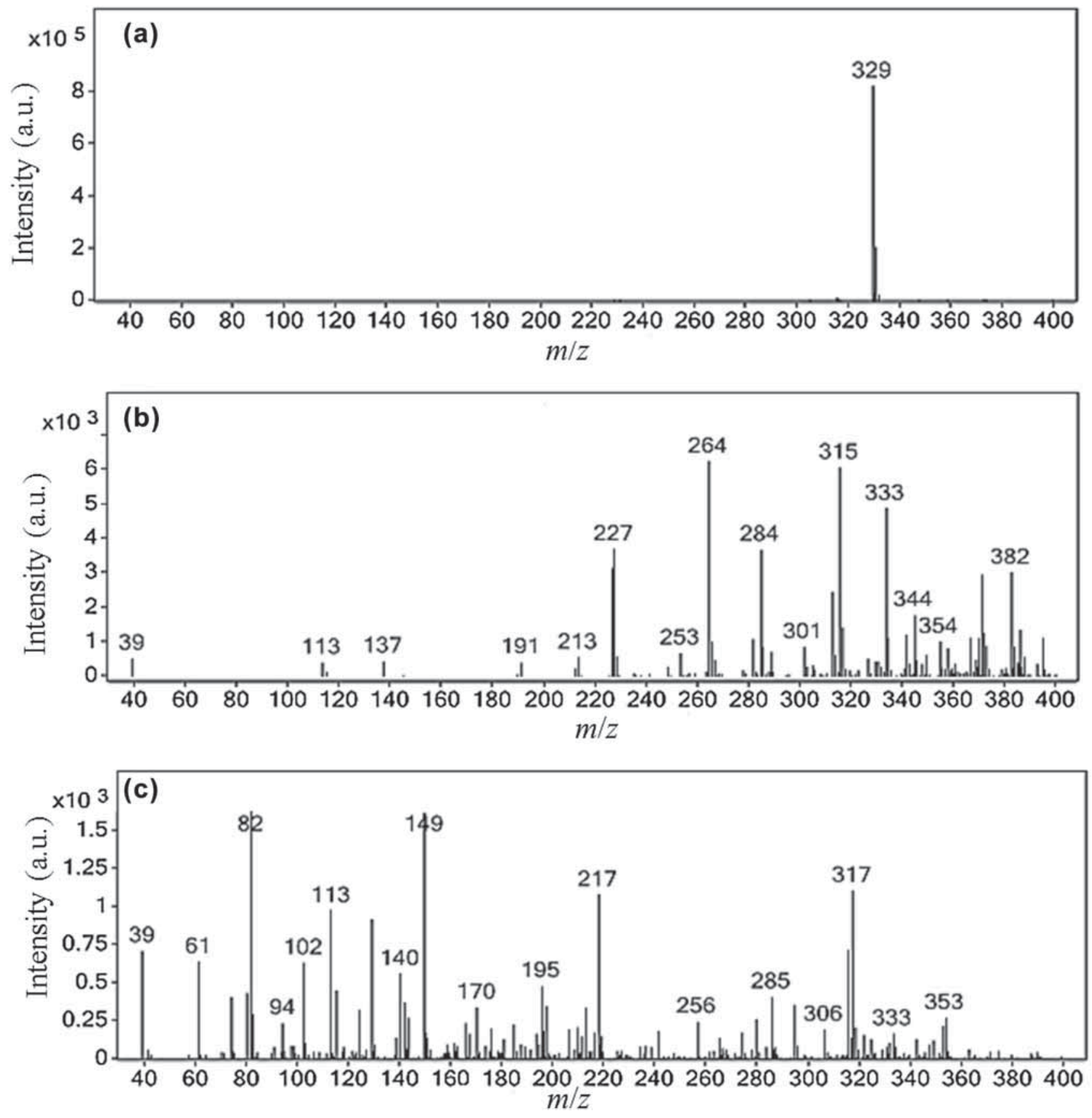

Figure 10. Mass spectra of (a) MG dye solution before solar irradiation and (b, c) after solar irradiation in the presence of ZnO NPs for 30 and 90 min, respectively. 
<smiles>CN(C)c1ccc(C(=C2C=CC(=[N+](C)C)C=C2)c2ccccc2)cc1</smiles>

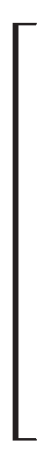<smiles>CN(C)c1ccc(C(=C2C=CC(=[N+](C)C)C=C2)c2ccccc2)cc1</smiles><smiles>CNc1ccc(C(=C2C=CC(=[N+](C)C)C=C2)c2ccccc2)cc1</smiles>

$m / z 315$

$m / z 301$<smiles>Nc1ccc(C(c2ccccc2)c2ccc(N)cc2)cc1</smiles><smiles>CN(C)c1ccc(C(=O)c2ccccc2)cc1</smiles>

$m / z 227$<smiles>CC=CCc1ccc(O)cc1</smiles>

$m / z 149$<smiles>[NH+][NH+]([Mg])c1ccc(C(=O)c2ccccc2)cc1</smiles><smiles>O=[N+]([O-])c1ccc(O)cc1</smiles><smiles>CN(C)c1ccc(O)cc1</smiles>
$\mathrm{m} / \mathrm{z} 140$ $m / z 137$<smiles>NCCCC(=O)O</smiles><smiles>CC(=O)O</smiles>

Figure 11. MG and its possible degradation products as analysed by LC-MS. 
2928, 2865, 2373, 1652, 1459 and $1108 \mathrm{~cm}^{-1}$, respectively. The shift observed in FTIR spectra of ZnO NPs after bioreduction bands such as 3420-3430, 2949-2982, 1637-1652, $1440-1445$ and $1106-1108 \mathrm{~cm}^{-1}$ indicate the participation of phenols, flavonoids, xenthones, anthocyanin, etc. with functional groups $\mathrm{OH}, \mathrm{C}=\mathrm{O}, \mathrm{COOH}, \mathrm{C}-\mathrm{O}-\mathrm{C}$, etc. in bioreduction reactions.

\subsection{Investigation of photocatalytic activity of biosynthesized $\mathrm{ZnO} N \mathrm{NPs}$ by degradation of MG dye under solar irradiation}

The photocatalytic activity of biosynthesized ZnO NPs was investigated by the degradation of MG dye in aqueous solution under sunlight irradiation. MG is a cationic triphenylmethane dye, and is one of the largest groups of hazardous dyes. It is commonly utilized in aquaculture industry as an effective fungicide [38], in textile industry as a colouring agent [39] and in industries of leather, paper and pharmaceutical, owing to its low price, readily availability and high efficiency [40]. Figure 7 shows the changes in the MG absorption spectra during photocatalytic degradation with $\mathrm{ZnO}$ nanophotocatalyst at different solar irradiation times varying from 0 to 180 min. About $99 \%$ of MG was degraded within 180 min of irradiation. Photodegradation of MG was also visually detected by gradual change in colour of the dye solution from bluishgreen to colourless (figure 8 ). The results show that MG dye with the strong absorption maxima at $615 \mathrm{~nm}$ due to the chromophoric group and it was getting diminished gradually with the increase in irradiation time and become invisible within $180 \mathrm{~min}$ of irradiation indicating that the chromophore in MG molecules was completely removed. It is also interesting to notice that a hypsochromic shift occurred simultaneously with increasing irradiation time and the maximum absorption wavelength shifts from 615 to $605 \mathrm{~nm}$. The hypsochromic shift is caused by an $N$-demethylation process [41]. The absorbance peaks at 425 and $315 \mathrm{~nm}$ were obviously disappeared under solar irradiation, which indicates that the entire conjugated structure of MG was destroyed. Notably, there is a new weak absorbance peak appeared at $355 \mathrm{~nm}$ after 90 min, which is possibly caused by benzene ring opening and cleavage of the central carbon.

The ratios of the concentration of dye, $C$ to the initial concentration, $C_{\mathrm{o}}$ of the dye $\left(C / C_{\mathrm{o}}\right)$ at different times of sun light exposure, were plotted against the time of sun light exposure to compare the efficiency of the degradation under various experimental conditions as shown in figure 9. It was noticed that only $6.25 \%$ degradation of MG dye was found when irradiated under natural sunlight in the absence of biosynthesized $\mathrm{ZnO}$ NPs, which is due to photolysis of MG. For the same MG dye solution, the degradation efficiency with biosynthesized $\mathrm{ZnO}$ NPs in the dark for 180 min was only $13.72 \%$, which can be attributed to the adsorption of MG on ZnO NPs. On the other hand, when the MG dye solution was exposed to the sunlight for $180 \mathrm{~min}$ in the presence of the biosynthesized $\mathrm{ZnO}$ NPs, the degradation efficiency of MG dye was almost
99\% because of efficient oxidation through hydroxyl radicals $(\bullet \mathrm{OH})$ produced from the photocatalytic reaction. The detailed mechanism is shown in scheme 2 . ZnO NPs successfully degraded MG dye into less harmful end products like $\mathrm{CO}_{2}, \mathrm{H}_{2} \mathrm{O}, \mathrm{NO}_{2}$, $\mathrm{NO}$, etc.

MG and the degradation products formed during the photodegradation process in the presence of $\mathrm{ZnO}$ NPs under solar irradiation were analysed by LC-MS and identified by interpretation of their mass spectra data presenting their molecule ion peaks with respect to $m / z$ (where $m$ is molecular weight of the intermediates in the mass spectra). Figure 10a represents the MS spectrum of MG dye in aqueous solution before irradiation and figure $10 \mathrm{~b}$ and $\mathrm{c}$ represents the MS spectra of MG dye in aqueous solution after solar irradiation for 30 and 90 min, respectively, with $\mathrm{ZnO}$ nanophotocatalyst. The parent molecular ion peak of MG at $329 \mathrm{~m} / z$ was detected before solar irradiation of the MG dye solution (figure 10a). However, after solar irradiation (for 30 and $90 \mathrm{~min}$, figure $10 \mathrm{~b}$ and c) the $\mathrm{m} / z$ at 329 was split into various mass $(\mathrm{m} / z)$ signals due to photodegradation of MG dye molecules in the presence $\mathrm{ZnO}$ photocatalyst. The possible degradation species detected by LC-MS from MG dye solution using biosynthesized $\mathrm{ZnO}$ NPs at different solar irradiation times are shown in figure 11.

The reaction kinetics of photocatalytic degradation of MG dye using biosynthesized $\mathrm{ZnO}$ NPs are also investigated using Langmuir-Hinshelwood kinetic model [42], whose equation is written below:

$$
\ln \left(C_{\mathrm{o}} / C\right)=k t,
$$

where $C_{\mathrm{o}}$ and $C$ are the concentration of MG dye solutions before and after solar irradiation, $k$ is the apparent rate constant which is obtained from the slope and $t$ the time duration of the photocatalytic reaction. Figure 12 displays

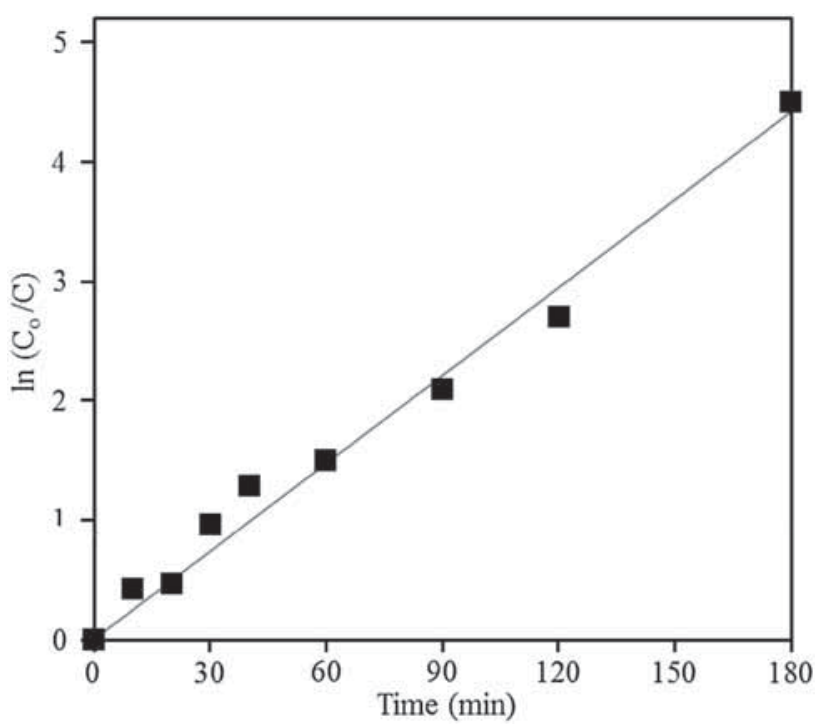

Figure 12. Plot of $\ln \left(C_{\mathrm{o}} / C\right)$ vs. time, displaying the photocatalytic degradation of MG dye. 
the plot of $\ln \left(C_{\mathrm{o}} / C\right) v s$. time. According to the equation, it was observed that the photocatalytic degradation of MG dye followed pseudo-first-order kinetics and the value of $k$ was found to be $0.0245 \mathrm{~min}^{-1}$.

\section{Conclusions}

In conclusion, we have developed an economically and environmentally benign, efficient and safe procedure for the green synthesis of ZnO NPs using G. mangostana fruit pericarp extract without use of toxic and hazardous materials. The detailed characterization results revealed that biosynthesised $\mathrm{ZnO}$ NPs are well-crystalline, possessing hexagonal wurtzite phase with an average size of $21 \mathrm{~nm}$ and exhibiting good optical properties. The photocatalytic activity of biosynthesized $\mathrm{ZnO}$ NPs was evaluated by the photodegradation of MG dye. The results indicate that the biosynthesized $\mathrm{ZnO}$ NPs have shown an excellent photocatalytic performance by almost complete degradation of MG dye on exposure to natural sunlight. Thus, biosynthesized ZnO NPs were proved as an effective photocatalyst, which can efficiently be utilized for the degradation of harmful and toxic pollutants persisting in aquatic environment.

\section{Acknowledgements}

We would like to thank Universiti Tunku Abdul Rahman (UTAR) for financial support and also providing all necessary facilities to carry out this research work successfully.

\section{References}

[1] Anirudhan T S, Suchithra P S and Radhakrishnan P G 2009 Appl. Clay Sci. $\mathbf{4 3} 336$

[2] Nassar M Y, Ahmed I S, Mohamed T Y and Khatab M 2016 RSC Adv. 620001

[3] Mittal A, Mittal J, Kurup L and Singh A 2006 J. Hazard. Mater. 13895

[4] Xu X, Gao B Y, Yue Q Y and Zhong Q Q 2010 J. Hazard. Mater. 1821

[5] Sarayu K and Sandhya S 2012 Appl. Biochem. Biotechnol. 167 645

[6] Yagub M T, Sen T K, Afroze S and Ang H M 2014 Adv. Colloid Interface Sci. 209172

[7] Verma A K, Dash R R and Bhunia P 2012 J. Environ. Manage. 93154

[8] Malik P K 2002 Dyes Pigment 56239

[9] Özgüra Ü, Alivov Ya I, Liu C, Tekeb A, Reshchikov M A, Doğanc S et al 2005 Appl. Phys. 98041301

[10] Bharti D B and Bharati A V 2017 Luminescence 32317

[11] Anžlovar A, Marinšek M, Orel Z C and Žigon M 2015 Mater. Des. 86347
[12] Ghoshal T, Biswas S, Paul M and De S K 2009 J. Nanosci. Nanotechnol. 95973

[13] Talebiana N, Amininezhada S M and Doudib M 2013 J. Photochem. Photobiol. B 12066

[14] Promnopas W, Thongtem T and Thongtem S 2015 Superlattices Microstruct. 7871

[15] Kumar S S, Venkateswarlu P, Rao V R and Rao G N Int. Nano Lett. 31

[16] Moharram A H, Mansour S A, Hussein M A and Rashad M 2014 J. Nanomater. 20141

[17] Omria K, Najeha I, Dhahria R, El Ghoula J and El Mira L 2014 Microelectron. Eng. 12853

[18] Jajarmi R, Zakaria A, Ahangar H A, Darroudi M, Zak A K and Drummen G P C 2012 J. Alloys Compd. 51641

[19] Yadav R S, Mishra P and Pandey A C 2008 Ultrason. Sonochem. 15863

[20] Ali K, Dwivedi S, Azam A, Saquib Q, Al-Said M S, Alkhedhairy A A et al 2016 J. Colloid Interface Sci. 472145

[21] Karnan T and Selvakumar S A S 2016 J. Mol. Struct. 1125358

[22] Zheng Y, Fu L, Han F, Wang A, Cai W, Yu J et al 2015 Green Chem. Lett. Rev. 859

[23] Nagajyothi P C, Ju S, Jun I, Sreekanth T V M, Joong K and Mook H 2015 J. Photochem. Photobiol. B 14610

[24] Dobrucka R and Długaszewska J 2016 Saudi J. Biol. Sci. 23 517

[25] Jafarirad S, Mehrabi M, Divband B and Kosari-Nasab M 2016 Mater. Sci. Eng. C 59296

[26] Anbuvannan M, Ramesh M, Viruthagiri G, Shanmugam N and Kannadasan N 2015 Spectrochim. Acta: Part A 143304

[27] Balaji S and Kumar M B 2017 Adv. Powder Technol. 28785

[28] Elumalai K, Velmurugan S, Ravi S, Kathiravan V and Raj G A 2015 Adv. Powder Technol. 261639

[29] Pedraza-Chaverri J, Cárdenas-Rodríguez N, Orozco-Ibarra M and Pérez-Rojas J M 2008 Food Chem. Toxicol. 463227

[30] Zein R, Suhaili R, Earnestly F, Indrawati and Munaf E $2010 \mathrm{~J}$. Hazard. Mater. 18152

[31] Zhou H, Wu L, Gao Y and Ma T 2011 J. Photochem. Photobiol. A Chem. 219188

[32] Umar A, Chauhan M S, Chauhan S, Kumar R, Kumar S, AlSayari S A et al 2011 J. Colloid Interface Sci. 363521

[33] Kumar R, Kumar G and Umar A 2013 Mater. Lett. 97100

[34] Salam H A, Sivaraj R and Venckatesh R 2014 Mater. Lett. 131 16

[35] Chandrappa K G, Venkatesha T V, Vathsala K and Shivakumara C 2010 J. Nanopart. Res. 122667

[36] Wang C, Shen E, Wang E, Gao L, Kang Z, Tian C et al 2005 Mater. Lett. 592867

[37] Obolskiy D, Pischel I, Siriwatanametanon N and Heinrich M 2009 Phytother. Res. 231047

[38] Rahman I A, Saad B, Shaidan S and Sya Rizal E S 2005 Bioresour. Technol. 961578

[39] Ju Y, Yang S, Ding Y, Sun C, Zhang A and Wang L $2008 \mathrm{~J}$. Phys. Chem. A 11211172

[40] Schnick R A 1988 Prog. Fish-Cult. 50190

[41] Behnajady M A, Modirshahla N, Shokri M and Vahid B 2008 Ultrason. Sonochem. 151009

[42] Hou J, Wang Z, Jiao S and Zhu H J 2012 Cryst. Eng. Commun. 145923 